\title{
Joining the information society: access issues for Europeans
}

Citation for published version (APA):

geuna, A., \& Steinmueller, W. E. (1996). Joining the information society: access issues for Europeans.

MERIT, Maastricht Economic Research Institute on Innovation and Technology. MERIT Research

Memoranda No. 014 https://doi.org/10.26481/umamer.1996014

Document status and date:

Published: 01/01/1996

DOI:

10.26481/umamer.1996014

Document Version:

Publisher's PDF, also known as Version of record

\section{Please check the document version of this publication:}

- A submitted manuscript is the version of the article upon submission and before peer-review. There can be important differences between the submitted version and the official published version of record.

People interested in the research are advised to contact the author for the final version of the publication, or visit the DOI to the publisher's website.

- The final author version and the galley proof are versions of the publication after peer review.

- The final published version features the final layout of the paper including the volume, issue and page numbers.

Link to publication

\footnotetext{
General rights rights.

- You may freely distribute the URL identifying the publication in the public portal. please follow below link for the End User Agreement:

www.umlib.nl/taverne-license

Take down policy

If you believe that this document breaches copyright please contact us at:

repository@maastrichtuniversity.nl

providing details and we will investigate your claim.
}

Copyright and moral rights for the publications made accessible in the public portal are retained by the authors and/or other copyright owners and it is a condition of accessing publications that users recognise and abide by the legal requirements associated with these

- Users may download and print one copy of any publication from the public portal for the purpose of private study or research.

- You may not further distribute the material or use it for any profit-making activity or commercial gain

If the publication is distributed under the terms of Article $25 \mathrm{fa}$ of the Dutch Copyright Act, indicated by the "Taverne" license above, 


\title{
Joining the Information Society: Access Issues for Europeans
}

\author{
by \\ Aldo Geuna \\ BETA, Univerisité Louis Pasteur Strabourg \& MERIT, Maastricht University \\ $\&$ \\ W. Edward Steinmueller \\ SPRU, University of Sussex \& MERIT, Maastricht University
}

Acknowledgements: The research and writing of this report was supported by the European Commission DG XIII within the ACTS Programme in the FAIR Project (AC093). The opinions and viewpoints expressed herein are those of the authors and may or may not accord with the views of members of the European Commission.

Contact author address: W.E. Steinmueller, SPRU, University of Sussex, Mantell Building, Falmer Brighton, BN1 9RF East Sussex, United Kingdom, Tel. +44-1273-678165, Fax. +44-1273-685865 e-mail: w.e.steinmueller@sussex.ac.uk 


\section{Introduction}

Advanced communications supporting the development of the information society is based upon the coevolution of data communication infrastructure and services. The technical capabilities of the data communication infrastructure are determined by the availability and features of modem communications, inter-networking of local area networks (LANs) and broadband connectivity. Advanced communication services (e.g. e-mail, online information service, Internet (and the World Wide Web) and audiovisual service are progressively developed and improved a the result of user experience an increasing technical capabilities of the data communication infrastructure. The ultimate purpose of these developments is to extend and improve the access and value received by users of advanced communications. The rate and direction of these developments will be shaped by who gains access to advanced communications and how services are developed through this access. This paper examines the issues of access for Europeans to the most widespread and heavily used of advanced communication services, the Internet, and the technological infrastructure supporting Internet access.

At present, gaining access to advanced communication services, and especially to advanced communication infrastructure, requires substantial technical expertise. Much of the expertise is embedded in organisations making extensive use of information and communication technology--e.g. universities, government offices and large enterprises. These organisations are able to fund the acquisition of the specialised skills and knowledge that are now necessary for accessing the information infrastructure, permitting their members to use advanced communication services. Some individuals with experience of advanced communication service use in organisations make an effort, with or without their organisation's assistance, to extend this environment into their home. Still other individuals, relatively few in number, independently develop enough expertise to be able to gain access to these services. Most of these 'independent' users are likely to have had substantial experience with personal computers.

This paper assesses what will be involved in extending access more broadly, both outside the structure of large, information and communication technology (ICT)-intensive organisations and within such organisations where decentralisation or downsizing often constrains the size and efficacy of user and technical support services. In addition to practical questions, such as how, when and where such access extensions will occur, we are interested in a deeper social question: how can we avoid the creation of information 'haves' and 'have nots' as we move in the direction of a highly technical information society? Answering these questions requires a deeper understanding of the economic determinants of the co-evolution of advanced 
communication infrastructure and services. It also requires a more detailed knowledge of the problems of user familiarisation and skill acquisition which are pre-requisites for broadening public access to both the commercial and non-commercial uses of advanced communications.

In this paper we focus on the costs of obtaining access to the Internet at the present stage of development for this portmanteau of services, including costs for enhancing the breadth and deepening the value of access. By breadth of access, we mean the organisational and technical structures by which large numbers of users can obtain low cost access to the Internet. To indicate a main theme of our argument, our interest in costs is broader than the issues of subscription fees to an Internet Service Provider (ISP) or the telecommunications costs of connecting to an ISP. ${ }^{1}$ Costs of acquiring, for oneself or from others, the relevant skills as well as the balance between return and investment in improving these skills are much more central to the user cost of information service access and hence to our interests.

Issues of user skills lead us directly to consider the challenge of 'deepening the value of access', which involves building the skills for using advanced communication services. In this process of skills deepening, our interest is in identifying 'trajectories' of user familiarisation and skills building that contribute to an individual's obtaining higher value in the use of the Internet over time. For some users, deepening will lead to more intense involvement in which Internet use will substitute for other forms of information acquisition while for other users, deepening value will simply lead to more rapid and effective access to desired information or services during the limited time they spend in using this medium. In both cases, we maintain the hypothesis that Internet use has the potential to enrich and improve the quality of life for a very diverse crosssection of the population. The validity of this hypothesis is neither obvious nor incontrovertible. It deserves closer examination and research than it has yet received. ${ }^{2}$

The Internet is an innovation both in interpersonal, i.e. point-to-point communication, and in broadcasting and publishing, i.e. point to multi-point communication. As a broadcast medium the Internet has the unique character that it can accumulate content from its users. It is the first medium with broadcast capabilities that is able to provide a tight 'feedback loop' between users

\footnotetext{
${ }^{1}$ An excellent study of the issues of ISP pricing and telecommunication costs is OECD, 1996.

2 The social impact of new communication technologies is rarely well understood during their formative years. See Marvin, 1988, for examples from the advent of the telephone. As Rosenberg, 1976 has noted, new technologies are neither robust or obvious replacements for existing methods. Indeed, as he also notes, they face difficult hurdles since their early success often stimulates the improvement of existing methods which become more competitive substitutes as the result. The study of advanced communication services as a new communication media has blossomed over forty years of research on media studies. See for example the pioneering studies of Innis, 1964 and McLuhan, 1994 and the contemporary lines of research synthesised and developed in Mansell and Silverstone (ed.), 1996. Even with the growth in sophistication of understanding, it is our suspicion that there will be a wide range of effects which simply cannot be anticipated because the process of learning and social interaction produces novelty.
} 
and producers of information. ${ }^{3}$ These technical characteristics of the Internet as a communication media suggest that it has a very wide range of potential application. The growth of the Internet, which we examine in detail below, is making it possible for individuals with very specialised interests, e.g. the preservation of Roman ceramics, to share knowledge and experience. This is a 'communication' application of the Internet. As a communication and information publication method, the Internet is also able to serve commercial interests, e.g. the sale of Roman ceramics, educational interests, e.g. the role of Roman ceramics in ancient commerce, hobby interests, e.g. means for reproducing the glazes used in Roman ceramics, etc. The example of Roman ceramics has a sophisticated tone, but everyday topics, such as bee keeping, cuisine, stain removal and carpentry, are equally amenable to such treatment. The potential to deliver information over the Internet does not suggest that people will in fact acquire information in this way. The value of alternatives such as books or videocassettes or even nonnetworked computer media such as CD-ROMs is also pertinent. The focus in this paper, however, will be on the problems of access.

A priori, we identify three possible styles of access to the Internet that arise from our discussion of the role of organisational support for advanced communication services. First, 'organisational' access in which the user is part of an ICT-intensive institution that provides to its members a connection (generally through a LAN), a personalised set of services (they range from basic e-mail and FTP, to specific intranet services) and technical support for the use of these services. ${ }^{4}$ Secondly, individual access in which information services are accessed from the home through a connection with an ISP or and on-line service offering Internet access. The services available depends on the type of service contract. Usually no training or in depth support is available (although, in some cases there are 24-hour telephone help lines). Third, 'community' access in which information services are accessed using a connection made

\footnotetext{
${ }^{3}$ This characteristic differentiates both the Internet and online services from existing media. By comparison, 'letters to the editor' or 'subscriber contributions' are features of print media while 'public access' television programmes are common in the US. In both cases, the user contribution is peripheral. In the case of the print media, publication delay and the 'hierarchical' relation between subscriber and editor (e.g. letters to the editor) make contributions marginal. In television, high production costs make it difficult for a public access channel to approach the 'state of the art' in production quality. All of these problems are present in the case of the Internet and online services, but are not yet as significant. In many respects, this is because of the newness of the media. It is, however, also the result of very low costs of access (low entry barriers) and the widespread availability of content creation tools which mean that individuals with specialised interests or knowledge can effectively compete with commercially financed content offerings. As a result, entirely new opportunities exist for 'democratising' expression.

${ }^{4}$ Organisations have many different policies concerning their members use of Internet services and organisations are establishing and revising policies at a rapid pace. Most commonly, these policies restrict the individual's use of the Internet for non-work related purposes. Enforcement of these policies requires monitoring of communications and may violate abridge basic principles of individual privacy, an issue that will certainly become as controversial as employee use of employer's telephones for personal purposes.
} 
available at public institutions --e.g. libraries, city halls, museums. ${ }^{5}$ In the cases of both online services and public institutions, access to basic Internet services (for example, World Wide Web (WWW) access) may be made available as an adjunct to other information.

At present, the costs of individual access are high. The availability of information appliancetype approaches may reduce this cost (e.g. Acorn or Oracle's efforts to develop Internet computers $^{6}$ or Philips' recent upgrading of its CD-I for Internet access). Another approach, which may have a larger impact in the short term, would involve a public access approach in which information terminals are provided in schools and libraries along with the training and familiarisation necessary to make use of such services. What would be the cost of providing public access in this way?

If a public access model is to be supported it will require a new class of technical support providers so that both information suppliers and users can focus on services rather than on infrastructure technology. How is the European market developing for Internet access providers (the entrance of PTOs in this market, e.g. Planet Internet NL, Video Online I), on-line service providers, system integrators, and others involved on both the supplier and user sides of the market? Are there significant barriers or bottlenecks that might be addressed by public policy?

Finally, attention should be given to the situation in the less favoured regions of Europe. The lack of policy action, particularly in the areas of education and training, may reinforce the actual economic and social disparities. Given the poor infrastructure situation of these regions, a market and demand driven development of the information services may result in an information society with major regional imbalances.

The paper is organised as follows. Section 2 discusses the access problematique in relation to the prospect of universal service for telecommunication. A quantitative analysis of supply and demand for information services and of the infrastructural situation will be developed in Section 3. The cost structure for the three types (nature) of access is presented in Section 4. Finally, in Section 5 the possible policy actions and the indications for further research are outlined.

\section{The access problematique and universal service provision}

\footnotetext{
5 The phenomena of the Internet cafe should also be consider in the picture. Although private activity, it is responding to the same need that the public access --i.e. access for people without an organisational or an individual access.

${ }^{6}$ See Vaughn-Nichols, 1996, for a review of these developments and a critique of their significance.
} 
The European Commission's introduction to "Universal Service for Telecommunications in the Perspective of a Fully Liberalised Environment", a Communication to the European Parliament, opens with an appeal to the crucial importance of communication: "To be able to communicate and interact whether by telephone, fax, e-mail or electronic media is a crucial and decisive factor for every citizen and business. The policy of the European Commission towards the information society has from the beginning taken into account the need to avoid a 'two-tiersociety', divided between those who have access to the new possibilities and are comfortable using them and those who are excluded from fully enjoying their benefits" (COM(96)73:p.2). Not only telephone and fax, but also e-mail and electronic media are considered crucial for every citizen and business. Furthermore, the Commission identifies the need to avoid the problems of information 'haves' and 'have nots' that arise from different degrees of access to the new media and by the diverse distribution of skills in using them.

In the section 'The evolution of the universal service for telecommunications and access to advanced services in the context of the information society' the Commission elaborates on the specific importance of advanced telecommunications services and of the new inter-active services especially in the areas of education and training, healthcare and access to public information. Nonetheless, the Commission states that "neither access to such services nor the services themselves should be included at this stage in the current concept of universal service." The diffusion of new and advanced telecommunications and information services is seen as the result of market forces and user demand.

There are certainly many cases where market forces do deliver plentiful supplies of desired commodities and services, but there are also cases where market forces are less effective. Relying on market forces presumes the pre-existence of knowledge and tends to ignore the issues of income distribution. It is a dubious assumption that knowledge about information services is sufficiently widespread to support informed choice and the role of public education in cultivating this knowledge is worth considering. Developing information access on the basis of ability to pay will lead to particular consequences which are worth comparing with alternative policies for public access (e.g. connecting HEIs, schools, libraries, hospitals, etc. on a Europeanwide basis). For example, it is important to understand the potential for a counter-cohesion feedback loop in which individuals with pre-existing knowledge or greater wealth, or individuals who are supported by larger organisations, have greater access to information that enhances their productivity and increases their wealth and the size of their organisations.

A key issue here is whether access to Internet services is a consumption or investment good. If it is the former, we should have less concern, since the feedback effects are likely to be smaller 
and the consequences of these effects are likely to be similar to other consumption activities. ${ }^{7}$ Similarly, in the less favoured European regions, as well as among other social groups, a large percentage of the population is neither computer nor network literate. Among these groups, the potential demand and the consequent market driven development is limited by the lack of knowledge. What are the potential consequences of public policies for market development?

A good example of the complementarity of public policies and market driven development is the Internet itself. In the US the first phase of development of Internet has heavily relied on public support, both to develop the technical sides of the system and to diffuse it in the research and education communities. The US government withdrew direct support of Internet only after the stabilisation of the technology and the widespread diffusion of Internet access in higher education and business, leaving the further development of the field to market and demand forces. In the European regions, where Internet access is not yet developed there may be a need for a first period of public support, to arrive at a situation where market forces will act with less disruptive and unbalancing effects. ${ }^{8}$

The Communication seems to take into account the issues ${ }^{9}$ and, consistent with the suggestions put forward in the interim report of the High Level Group of Experts, ${ }^{10}$ it seems to identify an important role for public and 'community' access in less favoured regions. Nonetheless, the possible policy initiative is postponed at least until early 1998, after the release of the Monitor Report, an important part of which seems to be devoted to the study of this problem.

A crucial distinction to be made is the one between access to the network and access to the service, the former does not guarantee access to information services (CSTB, 1994). The former depends on the development of the information and communication infrastructure (ICI) and, in particular, on the development of the "last mile technology." These are important issues in the Community's research and technology development (RTD) programmes such as ACTS. Within ACTS, there are at least eight projects devoted to the technical improvement of broadband access in ways that can directly support Internet usage. ${ }^{11}$ In addition, ACTS supports

\footnotetext{
7 For example, although improved culinary skills are regarded by many as a means for improving the quality of life, a relatively small amount of public resources are devoted to promoting this activity.

${ }^{8}$ In addition, France's special situation arising from the extensive development of Minitel raises questions of whether and how a common service infrastructure for European-wide advanced communication services will develop.

9 "The Commission must be vigilant against the danger that the different speeds at which territories of the Community equip themselves with the infrastructures, services and skills needed for the emerging information society may contribute to sustaining a "time gap" and to further widening of social and economic disparities. These issues must obviously be taken into account within the Community's cohesion policy” (COM(96)73:p.11)

10 "Building The European Information Society for Us All" Interim Report of the High Level Group of Experts. Especially Themes VI and VII, pp.40-56.

11 These projects are AMUSE (AC011) Advanced MUltimedia SErvices for residential users, ATHOC
} 
research on terrestrial and satellite wireless access that offers additional potentials for improving the information and communication infrastructure. All of these projects are oriented toward demonstration of feasibility with user trials to bring applications closer to commercialisation.

Technological capabilities for broadband access must, however, be contrasted with both the availability of access to such an infrastructure and the articulation of the market for such access. Without these further developments, the social and economic impacts of advanced communication services are more likely to follow the 'counter-cohesion' feedback loop noted above.

What are the requirements for these developments in advanced communication service use? First, there must be development of supportive service providers that offer users solutions to the technical problems of connection and the use of software tools. In other words, the advanced service access must be articulated and customised to the actual needs of users. At present, this articulation and customisation process is primarily left to market forces in the European Union. This situation contrasts markedly with the U.S. where the Clinton administration has committed to extending access to public institutions before the end of the decade and has made the first steps toward implementing this policy. Despite this, neither the US nor Europe has developed policies to address issues of technical support and the existing disparities between Internet users and the general population.

Second, the availability of relevant information services --e.g. in the case of public schools, the existence of mainstream education services. Some of these services are likely to be effectively provided by market development while others will require the further development of a 'public access' or 'social purpose' approach to services. European RTD programmes are making a contribution to the development of this area by supporting the development of technological capabilities within the ACTS and Telematics programmes. In ACTS three projects ${ }^{12}$ address the key issues of developing multimedia markets, network security and scalable server architectures for information content delivery. Specific 'social purpose' applications are being developed in the Telematics programme within seven areas - administration, education and training, environment, health, research, rural, and transportation. In addition, there are a series of support actions that aim to improve the impact of telematics developments on small and

(AC037) ATM Applications over Hybrid Optical Fibre Coax, BBL (AC038) BROADBANDLOOP, COBNET (AC069) Corporate Optical Backbone Network, IBCoBN (AC101) Integrated Broadband Communications on Broadcast Networks, INTERACT (AC086) Interactive Television Return Channel Standardisation And Trials, OPTIMUM (AC226) Optimised Network Architectures for Multimedia Services, and TOBASCO (AC028) TOwards Broadband Access Systems for CATV Optical Networks.

12 MULTI-MEDIATOR (AC096) Multimedia Publishing Brokerage Service, SEMPER (AC026) Secure Electronic Marketplace for Europe, and SICMA (AC071) Scaleable Interactive Continuous Media Server Design and Application. 
medium sized enterprises, regional development, and international relations. These RTD actions are essential for assuring that the 'non-commercial' sectors of European society are not left behind in the development of advanced communications.

Third, social cohesion is not only an issue of 'ability to pay' but also to issues of how different segments use the Internet. ${ }^{13}$ Substantial disparities in gender and age appear to exist between the population as a whole and the users of the Internet. The Graphic, Visualisation, \& Usability (GVU) Centre conducts the largest Web-based survey on WWW demography. ${ }^{14} 10.8 \%$ of the responses to the fifth survey, conducted in April-May 1996, came from Europe. The average age of European Web users is 28.8. In the Scandinavian countries where usage is higher as a percentage of the population, the users tend to be even younger, while the users Southern European are the oldest, on average. European women represented only $15.2 \%$ of the responding users, while in the US they account for $34.4 \% .^{15}$ The respondents' occupations tended to be either in education or computer-related business, and $79 \%$ of them held a college degree. ${ }^{16}$ Many of these disparities are likely to prove resistant to public policy and will only be overcome gradually through the permeation of advanced communication services such as the Internet in the general social fabric.

\section{Internet access in the EU: the current situation}

In analysing the current situation of Internet access in the EU we focus on four issues. First, what is the state of development of the information and communications infrastructure for accessing Internet services? Second, what indicators are available to tell us about the pattern of use of Internet services? This issue must be addressed indirectly as good measures of the use of Internet are as yet unavailable. ${ }^{17}$ Nonetheless, the number of hosts connected to the net, the most commonly used indicator, can give some idea about the trends of growth and diffusion of the system. Third, the market for Internet access providers has developed in different ways among the EU countries. This has strong implication for the distribution of the Point of Presence (POP) and for the future use of the net. Fourth, and finally, we will examine the current representation of educational, research, cultural, medical and public information access

\footnotetext{
13 Ability to pay is a significant issue as suggested by the observations that one third of the European users make more than the equivalent of $\$ 50,000$ (U.S.) a year. See the GVU Centre study at http:// www.cc.gatech.edu/gvu/ user_surveys as described below.

14 See http://www.cc.gatech.edu/gvu/user_surveys.

15 The participation of US women in the Internet is a relatively recent development, raising hopes that some closure of this gap will occur in the next two or three years. See Kantor and Neubarth, 1996, p. 50.

16 Values of the fourth survey, October-November 1995.

${ }^{17}$ For example, a computer can be connected full or part-time to the net, it can be used by one or more users and it
} 
to the Internet. ${ }^{18}$ Assessing the presence of libraries, Higher Education Institutions (HEIs), schools and museums on the WWW is a way to identify possible information 'have' and 'have not' situations among the EU countries.

\subsection{Information and Communication Infrastructure}

In Section 2 we have noted that a well developed ICI is not a sufficient condition for access to information services. It is, nonetheless, a necessary one. Currently, there are two main systems with the potential to access Internet. The first, and most broadly diffused one, is over a telecommunication line (telephone, basic rate ISDN line, or 'dedicated' or leased lines) using a communication device (a modem an ISDN modem, or more specialised data communications device). Regardless of the telecommunication connection method used, a personal computer is also required.

For telephone access, there are important technical issues about line noise and reliability for which no comprehensive data is available. Although ordinary voice lines are theoretically capable of supporting $28.8 \mathrm{kbps}$ modem traffic, the reality is often that this speed is unattainable - how often is unknown, typically even to the public telecommunication network operators until service complaints are received from users attempting to use this capacity.

In addition, the cost of telephone infrastructure depends upon the distribution of service 'points of presence' or the costs of making a dial-up connection to establish modem communication. In the US, this issue has been of secondary importance due to the widespread availability of nonmetered local calls. The National Academy notes "A major research focus of the last 10 years has been scaling network bandwidth to higher speeds (gigabits and beyond). Scaling in the number of nodes has perhaps received less attention" (CSTB, 1994) The scaling in the number of nodes has the potential for major impact on access costs in Europe due to metered local calling. If the access point to the network is out of the local area call distance, the use of Internet from home becomes extremely expensive. This is the case for rural areas, mountain areas and, more generally in the less favoured European regions.

The second system for gaining access is based on cable television systems and faces several sorts of problems. The first problem is the extent of pre-existing development of the cable network. In the US, cable television services have a $62 \%$ penetration of households with television (CSTB;1996) but, as yet, very little development of advanced communication services has occurred on this infrastructure. In the European Union, except for The Netherlands,

can be used for different purposes, with none of these differences being represented in currently available statistics.

18 Both in the US and in the EU different suggestions to develop policies to support the development of this part of the Internet have been recently put forward. See for example CSTB report on Realising the Information Future for the US, and The High Level Group of Experts Interim report for The EU. 
Belgium and Sweden, with respectively $101 \%, 105.7 \%$ and $57.3 \%$ penetration, ${ }^{19}$ cable service is not broadly diffused. This is both a problem and an opportunity, a problem because of the costs of establishing rights of way and construction and an opportunity because new systems may be built with advanced communication capabilities (either available immediately or with further investments in upgrades). In any case, the combination of low diffusion and the nascent state of development in the cable television networks' provision for advanced communication services means that this network is not yet well-positioned to offer a viable alternative for construction of advanced communication infrastructure. ${ }^{20}$

Table 1: Indicators of the Information and Communication Infrastructure

\begin{tabular}{|l|l|l|l|l|l|}
\hline & $\begin{array}{l}\text { Residential main } \\
\text { lines per 100 HH }\end{array}$ & $\begin{array}{l}\text { \% Digital lines } \\
\mathbf{1 9 9 4}\end{array}$ & $\begin{array}{l}\text { ISDN per 1000 } \\
\text { inhabitants } \\
\mathbf{1 9 9 5}\end{array}$ & $\begin{array}{l}\text { PC per 100 } \\
\text { inhabitants } \\
\mathbf{1 9 9 4}\end{array}$ & $\begin{array}{l}\text { Cable TV Sub. } \\
\text { \% of TV HH } \\
\mathbf{1 9 9 4}\end{array}$ \\
\hline Austria & $>100$ & 46.3 & 2.1 & 10.74 & 39.2 \\
\hline Belgium & 84.9 & 60.0 & $0.9 * *$ & 12.90 & 105.7 \\
\hline Denmark & $>100$ & 53.3 & 3 & 19.33 & 32.3 \\
\hline Finland & $>100$ & 77.0 & 1.3 & 15.94 & 42.7 \\
\hline France & $>100$ & 89.0 & 5.4 & 13.96 & 7.9 \\
\hline Germany & 89.1 & 45.0 & 6.4 & 14.36 & 45.2 \\
\hline Greece & 88.7 & 31.4 & 0.03 & 2.88 & 0 \\
\hline Ireland & 70.1 & 68.0 & 0.66 & 13.83 & $46.2 *$ \\
\hline Italy & 96.8 & 67.4 & 0.85 & 7.21 & 0 \\
\hline Netherlands & 92.8 & 100.0 & 1.5 & 15.59 & 101.0 \\
\hline Portugal & 79.9 & 62.0 & 0.81 & 4.98 & 0 \\
\hline Spain & 92.5 & 47.8 & 0.27 & 6.95 & 2.7 \\
\hline Sweden & $>100$ & 67.0 & 2.8 & 17.17 & 57.3 \\
\hline UK & 96.9 & 82.7 & $0.9 *$ & 15.15 & 4.5 \\
\hline
\end{tabular}

Source: Adapted from ITU, 1995, and ONPCOM96-24bis.

* : 1993.

**: 1994.

Table 1 shows the available indicators for the diffusion of ICI in the EU countries. The basic indicator of accessibility to telephone (and low speed modem use), residential main lines per 100 households, indicates that, except for Ireland, the EU countries are at the point of market saturation for basic telephone services.

19 Higher than $100 \%$ penetrations in Belgium and The Netherlands are a result of the division total subscriptions (which include business and other institution subscriptions) by the number of households with televisions. Finland, Germany and Ireland also have significant (around 45\%) penetration of cable TV (see Table 1).

20 A third alternative, wireless, is at an even more primitive state of development. Europe may have significant advantages in this area over a longer horizon because the widespread use of GSM has given mobile operators substantial experience with digital technology. 
Digital lines --i.e. lines connected to digital exchanges-- allow a higher quality transmission of information compared to the lines connected to electro-mechanical switching systems. The situation in the EU is heterogeneous. Four countries, Austria, Germany, Greece and Spain, have a share of digital lines lower than $50 \%$. Only The Netherlands has a completely digitised system. The value of the other EU countries varies between $53.3 \%$ of Denmark and $89 \%$ of France although in all countries, urban centres have much higher rates of digital line connection.

An increase in quality in data transmission can also be realised with the use of the Integrated Service Digital Network (ISDN) access. While telephone line data communication is bounded to speeds near the widespread standard of $28.8 \mathrm{Kbps}$, with basic rate ISDN, a speed of $64 \mathrm{Kbps}$ on each of two lines is possible. ${ }^{21}$ In 1995, ISDN has still a limited diffusion. EU countries can be subdivided into three main groups in relation to the penetration of ISDN. ${ }^{22}$ At the highest end France and Germany with respectively 5.4 and 6.4 ISDN subscribers per 1000 inhabitants. At the lowest end Greece, Ireland, Italy, Portugal and Spain have values lower than 1 . The other countries have figures ranging between 1.3 and 3. Practically speaking, ISDN is sufficiently undeveloped that it may be considered at the 'starting gate' along with cable television or other technological possibilities for upgrading telephone lines.

Currently a combination of a telecommunication line and a personal computer (PC) is the main method to access the Internet. The only figure available at a cross-country level for the EU to analyse the computer diffusion is the number of PCs. No distinction between business and home is available. Nonetheless, the number of PCs per 100 inhabitants is useful to quantify the information technology intensity of a country. EU countries split into two clusters, one with more than 10 PCs per 100 inhabitants and one with less. The latter includes Greece, Italy, Portugal and Spain.

The total number of PCs is not a good indicator of potential access from home --i.e. individual access. Due to the relatively high performance required to run applications such as WWW, the share of households with a home-PC is also inadequate as there is a significant stock of earlier generation PCs in homes. We assume that the availability of a CD-ROM drive is a better minimum or lower bound indicator of the number of PCs with high enough performance to manage Internet applications. ${ }^{23}$ The potential for individual access can thus be bounded

\footnotetext{
${ }^{21}$ Somewhat higher phone line rates are possible using compression or other methods, but are usually proprietary. For ISDN, the basic rate interface has two lines, while the primary rate has 30 lines making speeds of $1.92 \mathrm{Mbps}$ for the latter a possibility.

${ }^{22}$ Belgium and UK are excluded from this analysis due to the unavailability of the values for 1995.

23 A computer of this type complies with the so-called Multimedia PC (MPC) standard. Estimates suggest that about $18 \%$ of home PC are MPCs.
} 
between the share of households with a CD-ROM drive on the bottom and the share of households with a home PC as an unrealistic top (although not completely unrealistic as a significant number of home offices with higher performance computers exists and such technologies have dual personal and business use). In December 1995 the share of households with a home-PC ranged between a high of $27 \%$ for Sweden and a low of $10 \%$ of Greece, while the share of households with a CD-ROM drive ranged between a high of $11 \%$ of Germany and a low of 3\% of Greece. As illustrated in Figure 1, the two indicators have similar patterns in all the countries except for Spain and UK where advanced PCs seem to be less thoroughly diffused. Denmark, Germany, The Netherlands and Sweden have the highest shares among the countries considered.

\section{Figure 1: Share of Households with Home-PC and CD-ROM}

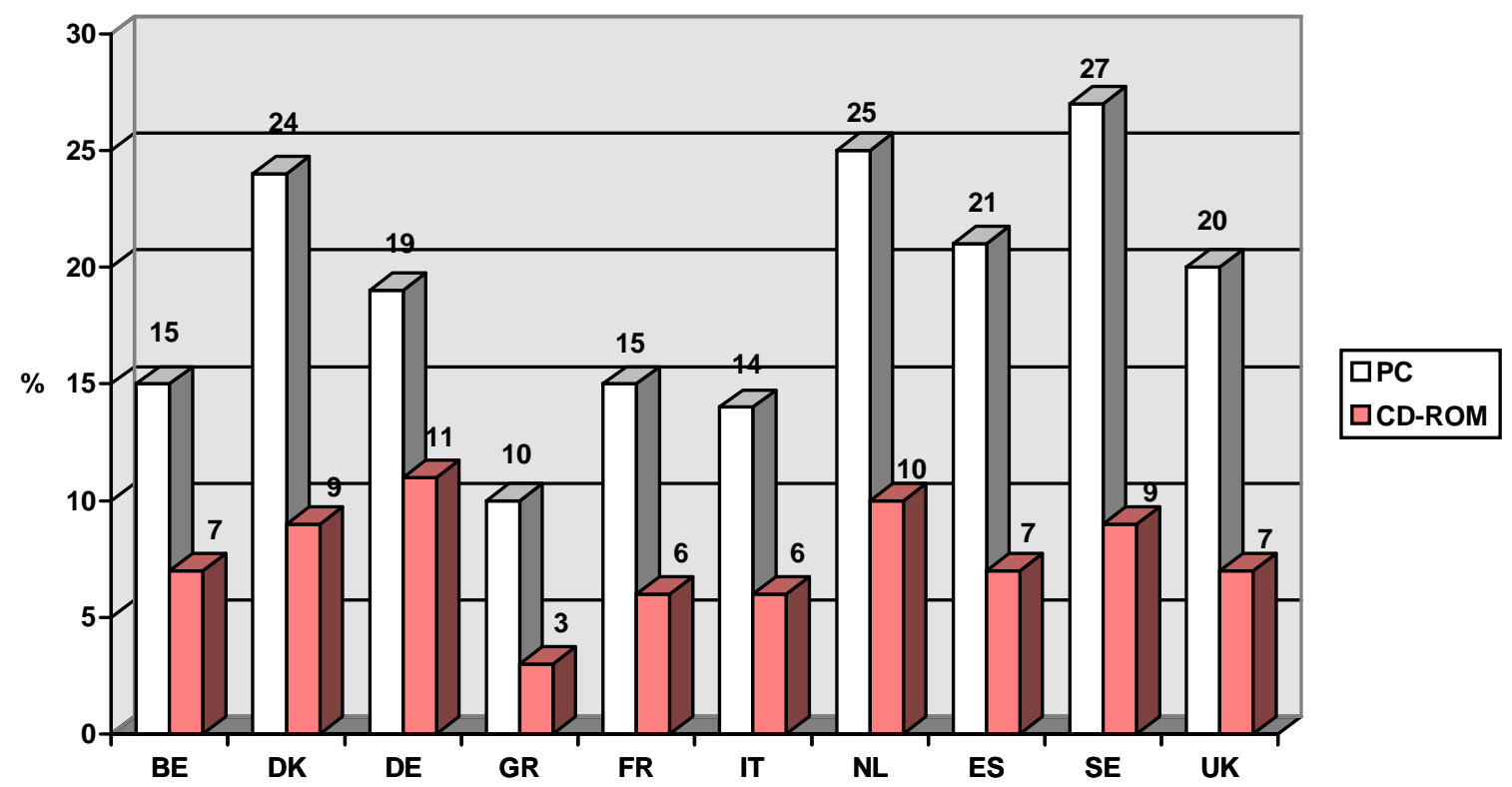

Source: Adapted from figures from Inteco, http://www.inteco.com/data1.html DE includes only the West Germany.

Consideration of all the indicators together highlights how Greece is the country of the EU in which ICI is currently least developed. Italy, Portugal and Spain also tend to have a lessdeveloped ICI. At the other extreme, Denmark, Sweden and, given the recent diffusion of ISDN, the UK, have better infrastructure. France also has high values except for the penetration of PC and CD-ROM in the home, indicating a business bias in the information and communication development in that country. Finland, Germany and The Netherlands show a strong position, with however some weaknesses. The situation of Austria and Belgium is somewhere in the middle, with no particular strong or weak points. Finally, Ireland is in a 
mixed situation. With the lowest share of residential main lines per 100 households, there are clearly still problems with the basic telecommunication infrastructure. Nonetheless, this indicator has shown a rapid growth in the last several years. As digital lines and PC penetration have average values, it seems that Ireland has an ICI developing later than the most advanced countries, but is able to take advantage of this 'relative backwardness' to adopt more recent technology.

The most relevant conclusion from our analysis of the information and communication infrastructure in the EU is that the systems of all the southern European countries are remarkably less developed than that of the other EU partners.

\subsection{Internet diffusion}

Internet is composed of a set of utilities that allow the transmission of data, images, video and voice. There are seven principal components. They are: FTP, Telnet, Netnews, e-mail, Gopher and World Wide Web (WWW). Up to March $1995^{24}$ the NSFNET was providing statistics on what data were sent over the backbone. These figures show an extremely rapid growth of the WWW. From the last available figures, WWW accounted for slightly less then a quarter of the total flow on the backbone. A conservative estimate would place the current value for WWW at something comprising $60 \%$ and $70 \%$. The fast growth of WWW becomes evident when we consider that in the period July 1995, July 1996 the number of web sites ${ }^{25}$ increased from 23,500 to the estimate value of 230,000 .

Table 2: $\quad$ Number of Hosts, top level domain

\begin{tabular}{|l|l|l|l|r|c|}
\hline & July 1996 & Jan 1996 & Jan 1995 & Jan 1994 & Jan 1993 \\
\hline USA & $8,224,279$ & $6,053,402$ & $3,178,266$ & $1,475,422$ & 942,693 \\
\hline com & 3,323647 & $2,430,954$ & $1,316,966$ & 567,686 & 347,486 \\
\hline edu & $2,114,851$ & $1,793,491$ & $1,133,502$ & 605,402 & 410,940 \\
\hline net & $1,232,902$ & 758,597 & 150,299 & 12,608 & 9,986 \\
\hline gov & 361,065 & 312,330 & 209,345 & 129,134 & 79,772 \\
\hline org & 327,148 & 265,327 & 154,578 & 50,544 & 31,490 \\
\hline mil & 431,939 & 258,791 & 175,961 & 103,507 & 62,327 \\
\hline us & 432,727 & 233,912 & 37,615 & 6,541 & 692 \\
\hline EUROPE & $3,017,784$ & $2,284,750$ & $1,106,077$ & 587,135 & 303,828 \\
\hline Others & $1,638,937$ & $1,133,848$ & 567,657 & 154,443 & 66,479 \\
\hline Total & $12,881,000$ & $9,472,000$ & $4,852,000$ & $2,217,000$ & $1,313,000$ \\
\hline
\end{tabular}

Source: Adapted from figures from Network Wizards, http://www.nw.com; RIPE NCC, http://www.ripe.net

\footnotetext{
24 In April 1995 NSFNET stopped running the backbone.

25 The source of this data is Matthew Gray of MIT. He defines a web site as all documents with urls beginning with a unique host name. http://www.mit.edu:8001/people/mkgray/net/index.html.
} 
The most common way to quantify the size of Internet is a count of 'hosts' ${ }^{26}$ This indicator does not give the exact size of the Internet, and does not allow an estimate of how many users are connected. Nonetheless, it does highlight the dynamic trends in the system.

To estimate the extent of European presence, we focus on the high-level domain name of known server addresses. Although it is possible for European institutions to be classified with a top level domain name such as com, edu, net and org, we use the sum of these four domains plus the domains gov, mil and $u s$ as an estimate of the US dimension. ${ }^{27}$ The European dimension is given by the sum of the hosts with a top level domain name of European nationality, also in this case part of the domain names referring to European countries may be located outside Europe.

The growth of hosts seems to have stabilised at a rate of slightly less then doubling every 12 months. The current value, proportional to the values calculated in the first half of the year during the previous periods, confirms the trend of constant (exponential) growth. ${ }^{28}$ In level, Europe is lagging the U.S. by about 15 months. The similar rate of growth means that, at present, there is no prospect for catching up. In the category 'others', $80 \%$ is comprised of Japan, Canada and Australia, and these host domains have a faster rate of growth than either US and Europe.

Table 3: $\quad$ Number, Growth and Intensity of Hosts.

\begin{tabular}{|l|l|l|l|l|l|l|l|}
\hline & July 1996 & Jan 1996 & Jan 1995 & Jan 1994 & Jan 1993 & $\begin{array}{l}\text { CAGR } 93 \\
\text { '96-96 }\end{array}$ & $\begin{array}{l}\text { Hosts per } \\
\text { 100 PC }\end{array}$ \\
\hline Austria & 76,499 & 60,320 & 28,928 & 12,587 & 9,286 & 86 & 6.7 \\
\hline Belgium & 44,358 & 31,920 & 19,065 & 7,544 & 1,658 & 168 & 2.8 \\
\hline Denmark & 80,182 & 52,536 & 27,348 & 8,703 & 5,383 & 113 & 6.1 \\
\hline Finland & 301,337 & 230,473 & 71,639 & 35,705 & 19,606 & 127 & 29.2 \\
\hline France & 194,131 & 145,830 & 94,112 & 56,675 & 25,719 & 78 & 2.0 \\
\hline Germany & 603,790 & 467,024 & 209,268 & 120,034 & 66,043 & 92 & 3.9 \\
\hline Greece & 11,896 & 9,111 & 4,030 & 1,935 & 699 & 135 & 3.0 \\
\hline Ireland & 21,483 & 13,688 & 6,327 & 2,330 & 1,284 & 120 & 3.8 \\
\hline Italy & 119,952 & 78,255 & 32,334 & 18,027 & 8,725 & 108 & 2.1 \\
\hline Netherlands & 216,153 & 177,050 & 89,279 & 44,917 & 25,217 & 91 & 7.6 \\
\hline Portugal & 15,776 & 12,698 & 5,521 & 3,382 & 1,901 & 88 & 2.3
\end{tabular}

${ }^{26}$ A host is "a domain name that has an IP address (A) record associated with it. This would be any computer system connected to the Internet" (http://www.nw.com/zone/www/defs.html). The combinations name/IP address are managed by the Domain Name System.

27 Traditionally, the preponderance of European organisations in all of these classifications have identified themselves by their country rather than the functional purpose of their site. This is subject to change over time and given the very large number of organisations, it will prove extremely difficult to determine nationality without devising some technique for making estimates other than those existing at present

28 For an estimation of the growth up to 2000 see ftp://ftp.isoc.org/isoc/charts2/growth/90s-host.txt. This estimation, done by the Internet Society in 1995, up to now has values very near to the real one. 


\begin{tabular}{|l|l|l|l|l|l|l|l|}
\hline Spain & 85,698 & 56,604 & 27,040 & 15,155 & 6,578 & 105 & 2.4 \\
\hline Sweden & 190,484 & 153,574 & 79,658 & 42,251 & 26,648 & 79 & 10.3 \\
\hline UK & 579,756 & 458,927 & 240,299 & 117,076 & 53,599 & 104 & 4.8 \\
\hline EU TOTAL & $2,543,491$ & $1,950,006$ & 936,843 & 488315 & 254339 & 97 & 4.4 \\
\hline
\end{tabular}

Source: Adapted from figures from RIPE, http://www.ripe.net. * : 1996. Estimate of PC in 1996 from ITU data. When we consider the total number of hosts in the European Union (see Table 3) we find a pattern of development similar to that of the US. However, the country specification shows important differences. Eight countries more than double their values each year, and of these all were countries that started from low values except for Portugal and Austria. The countries that started with a consistent $(>10,000)$ number of hosts less then double their values each year. Exceptions are Finland and the UK, which have sustained and high growth rates.

The intensity of the Internet diffusion can be analysed by both the number of hosts per $100 \mathrm{PC}$ and the number of hosts per 100 inhabitants. The former shows that, relative to the information technology base, Finland, Sweden and, to a lesser degree the Netherlands and Denmark, have a large involvement in the Internet, while France, Italy, Portugal, Spain and, to a lesser degree Belgium and Greece, tend to have a lower penetration of Internet hosts. The number of hosts per 100 inhabitants follows a similar pattern. Finland, Sweden, The Netherlands and Denmark have the highest values, while Greece, Portugal, Italy, Spain and France have the lowest.

\section{Figure 2: Number of Hosts per 100 Inhabitants}

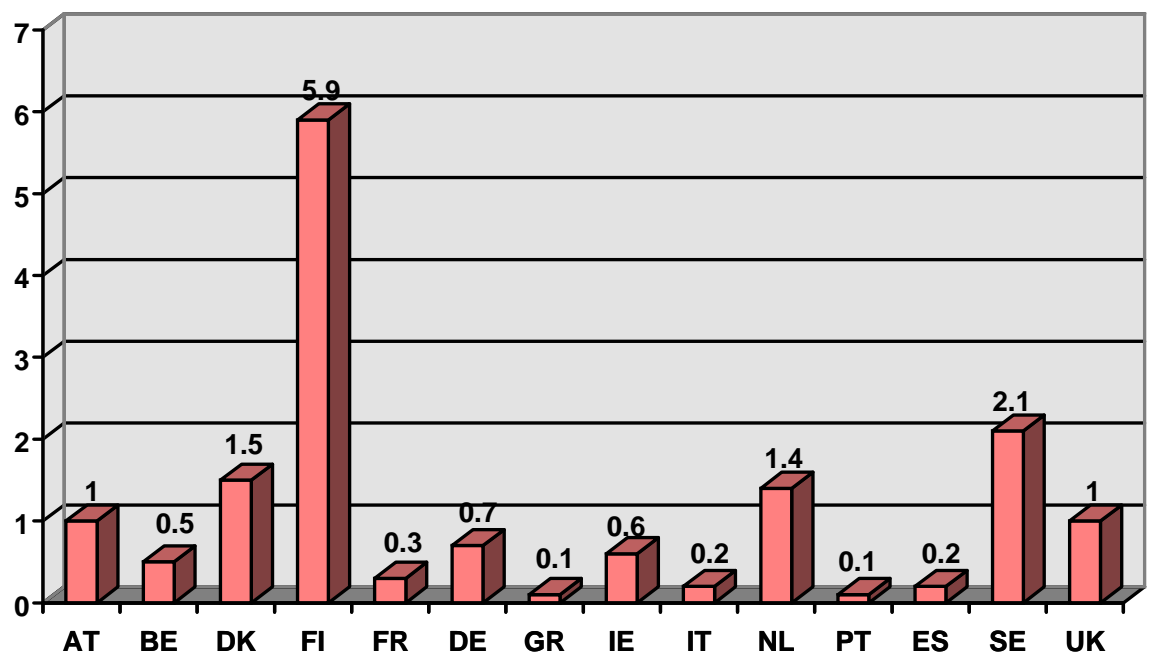

The diffusion of the Internet in the EU is characterised by strong national heterogeneity. On the one hand, the southern European countries, with less-developed ICIs, have low levels of Internet diffusion. Nonetheless, except for Portugal, they have witnessed growth rates higher then the EU average. On the other hand, Sweden, Denmark, Finland and The Netherlands have high 
level of Internet penetration. For the first two, the Internet phenomenon is just part of broader development of ICI, while for the last two the level of Internet diffusion is higher than could have been expected from the level of development of their ICI. Particularly in the case of Finland, the high number of hosts per 100 inhabitants may be the result of policy initiatives favouring the rapid growth of Internet usage in higher education and more broadly throughout society. Finally, although it has a well developed ICI, France has the lowest level of Internet diffusion. This may be explained by the business bias in the use of PCs highlighted above, and by the high diffusion of Minitel, which is a substitute for many features of the Internet on both the supply and demand sides of the market.

As in the ICI case, a divide between the southern European countries and the other EU members is present. If we view Internet as the forerunner of future information services, and particularly if the Internet, itself, will evolve from its current position to higher levels of service, serious policy initiatives have to be considered to avoid the perpetuation of major regional imbalances.

\subsection{Internet Service Providers}

During the early period of Internet diffusion there were three clearly distinguishable categories of Internet providers: Internet Access Providers (IAPs), Internet Service Providers (ISPs) and Online Service Providers (OSPs). The first specialised in selling an IP connection, while the second sold access plus basic services. OSPs began from a position of offering their own user interface and a range of specialised services such as access to online databases, chat lines for simultaneous user interaction, 'electronic magazines' and various kinds of user forums. ${ }^{29}$ With the rapid growth of the Internet, many OSPs have added Internet access as a feature of their service. Currently the differences between the first two categories of providers have largely disappeared, due to IAPs' offering additional services. Although the distinction between ISPs and OSPs is blurring as ISPs add further services, there are still distinctions in the user interface, service bundles, and identification of the two types of service. OSPs retain a distinct sense of identity and provide a 'home base' from which users venture into the larger and more chaotically organised Internet while ISPs generally take their subscribers' interests to be focused on the Internet, and try to augment or enhance the use of Internet access rather than to offer substitutes or a 'sheltered' environment for the user.

No consistent data on ISPs are currently available. In the WWW, one can find different sites offering lists of ISPs, but by comparing them it is clear that none of them is sufficiently comprehensive to serve as a census for the purpose of cross-country analysis. ${ }^{30}$ In Europe local

\footnotetext{
29 For example, Compuserve and UK Online are OSPs.

30 Particularly interesting is The directory, http://www.vni.net/thedirectory. It offers listings of Internet access providers (dial-in) and BBS at a world-wide level.
} 
Internet Registries (IRs) are operated by ISPs that offer IP registration services to their customers. Major ISPs receive IP address identification directly from the RIPE $\mathrm{NCC}^{31}$ rather than from an upstream provider. ISPs that register directly with RIPE NCC become the local IRs. Thus, it is possible to assume that all important ISPs operating in a country are local IRs too. In the following analysis we use the number of local IRs as a proxy for the number of ISPs.

Table 4 shows the current values of: a) the number of local IRs -- i.e. Internet providers-- in the EU countries broken down by dimension (service providers are classified in small, medium and large size by the RIPE NCC for billing purposes), b) the number of local IRs per 10,000 hosts, and c) the share of foreign IRs active in the country. The total number of local IRs ranges between 11 providers in Greece and 80 in the UK.

\section{Table 4: $\quad$ Internet Registries}

\begin{tabular}{|l|l|l|l|l|l|l|l|l|l|l|l|l|l|l|}
\hline & AT & BE & DK & FI & FR & DE & GR & IE & IT & NL & PT & ES & SW & UK \\
\hline Large & 4 & 4 & 3 & 3 & 6 & 6 & 3 & 3 & 6 & 6 & 4 & 6 & 8 & 15 \\
\hline Medium & 4 & 3 & 6 & 6 & 8 & 6 & 3 & 4 & 6 & 4 & 1 & 1 & 6 & 11 \\
\hline Small & 18 & 13 & 7 & 6 & 21 & 41 & 5 & 5 & 32 & 12 & 9 & 11 & 7 & 54 \\
\hline Total & 26 & 20 & 16 & 15 & 35 & 53 & 11 & 12 & 44 & 22 & 14 & 18 & 21 & 80 \\
\hline IR 10000 & 3.4 & 4.5 & 2 & 0.5 & 1.8 & 0.9 & 9.2 & 5.6 & 3.7 & 1.0 & 8.9 & 2.1 & 1.1 & 1.4 \\
\hline Int. IR \% & 23.1 & 45.0 & 50.0 & 53.3 & 45.7 & 28.3 & 63.6 & 50.0 & 22.7 & 40.9 & 50.0 & 38.9 & 47.6 & 11.3 \\
\hline
\end{tabular}

Source: Adapted from figures from RIPE, http://www.ripe.net

The number of IRs per 10,000 hosts can be used as an approximate indicator of the concentration of the market. Three groups can be identified. At one extreme, Finland, Germany, The Netherlands, Sweden and the United Kingdom have values ranging between 0.5 and 1.4, at the other extreme, the values of Austria, Italy, Belgium Ireland, Portugal and Greece range between 3.4 and 9.2. In the middle, France, Denmark and Spain have values of about 2.

When we look at the number of foreign providers, Denmark, Finland, Greece, Ireland and Portugal have $50 \%$ or more IRs that are based in other European countries or are "EU providers." 32 The other EU members have a lower number of foreign IRs. The lowest share is that of the UK with only 11.3 non-UK providers.

\footnotetext{
31 TheRIPE Network Coordination Centre is the Regional Internet Registry for Europe and surrounding areas. Internet Network Information Centre (InterNIC) is the regional registry for America, and APNIC is the one for the Asian Pacific region.

32 Registry based in the EU means US providers serving EU countries, or European providers serving a large number of EU countries, with a general EU registration.
} 
In Figure 3 we have shown the distribution of IRs by size. In eight countries ${ }^{33}$ more than $60 \%$ of service providers are classified as 'small' for RIPE NCC billing purposes. In the other six member states, small IRs have shares comprising between $33 \%$ and 55\%. In only two countries, Sweden and Finland, is the share of small providers less than $40 \%$.

\section{Figure 3: Dimensional Distribution of Local IRs, by Countries}

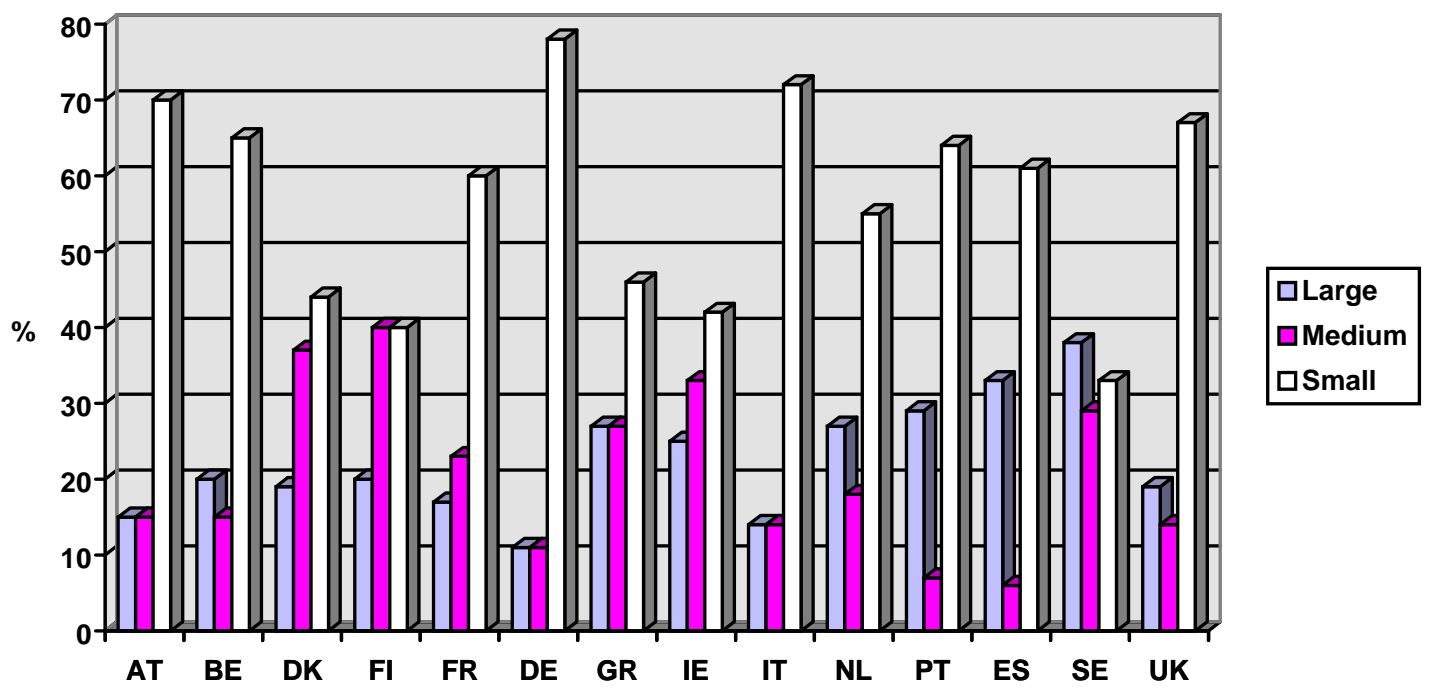

By combining the approximate indicator for ISP concentration given by the number of providers per 10,000 hosts and the distribution by size class of the providers, the Finish, Swedish, Dutch and, to a lesser extent, Danish markets for Internet access tend to be more concentrated than in other EU countries. The situation is less clear for Germany and the UK. In both countries there are a low number of providers compared to the number of hosts, but they also have an extremely high share of IRs of smaller size class. A topic for further research would be to determine whether this distribution reflects a relatively unstable 'competitive fringe' that is subject to shake out or a more stable development of specialisation in which there are 'broad market' and 'narrow market' participants. The other countries have a lower level of market concentration.

One of the reasons for different market concentrations is the dynamic of the development of the Internet. In the section on Internet diffusion (Section 3.2) the four countries that have higher market concentration have a high level of Internet penetration, both currently and historically.

33 The countries are Austria, Belgium, France, Germany, Italy, Portugal, Spain and United Kingdom. 
Thus, the actual level of concentration in their markets of Internet providers is the result of an early development, that has allowed a longer period for selection among the competitors.

\subsection{Educational, research and cultural aspects of the $W W W^{34}$}

The 'public' part of the Internet is recognised as an area where the impact of access policies is not only welcome, but also required. Education, research, cultural, medical and public information form the 'public' part of the Internet.

In this section we focus in particular on the existence of sites that offer education, research and cultural information. The presence of sites accessible through Telnet, Gopher or WWW indicate not only the availability of information for potential users, but also the existence of a physical location where it is possible to access the Internet and where, in some cases, technical support may be available for Internet use. Due to the dominant role played by WWW in recent Internet development and to the WWWs' user-friendly characteristics that support faster user acceptance, we assess the participation of libraries, schools, HEIs and museums as WWW sites as an indicator of public access to the Internet. The indicators differ for each of these institutions, so we examine them one at a time and then summarise the findings.

Three different types of access are available for libraries. A user can access the library catalogue via Telnet section, gopher service or World Wide Web. Usually, the access method for a library is the service offered by the library to connect with other institutions. For example, if the library makes its catalogue available using Telnet, it is also likely to have Telnet services for accessing other libraries, but is then less likely to have a WWW presence, or to have only a very limited WWW connection. In other words, the pre-existence of electronic library catalogues is a barrier to the growth of WWW-based library services since a 'good enough' solution exists for many users and the costs of changing the interface would make obsolete many existing user skills. ${ }^{35}$ According to UNESCO there were 27,000 libraries with 41,000

\footnotetext{
34 Due to the fast growth of the Web and to the difficulty of identifying new servers the figures given should be only considered as an indication of the possible dimension and not as the correct values.

35 In principle, little substantive difference in the user interface and search methods would be necessary to implement a WWW version of many library systems. In practice, however, many of these systems are of proprietary design and were sold to libraries as 'turn key' systems with upgrading and maintenance performed by the original supplier. Restructuring the databases and reintegrating the database with WWW server software is a non-trivial system design task in which some delay is to be expected. The issue of access rights is of minor significance as the addition of password protection to a WWW site is an easy task assuming that user response for searches is already part of the system.
} 
service points in the EU during the $1990-1992$ period. ${ }^{36}$ Of these only about $300^{37}$ had same sort of connection to Internet in July 1996, of which more than two thirds are university libraries. With respect to public libraries, four countries, Finland, The Netherlands, Sweden and the UK, with respectively 20,16,14 and 28 institutions, account for about $80 \%$ of the public libraries on the WWW. Less favoured regions, and in general the southern European countries show a very low penetration of Internet in the public library system. The high level of library connection in Finland is the consequence of the early adoption of WWW in the public library system - Helsinki City Library was the first public library in the world to put up a WWW server.

Table 5: $\quad$ Schools on the WWW

\begin{tabular}{|l|l|l|l|l|l|l|l|l|l|l|l|l|l|l|}
\hline & AT & BE & DK & FI+ & FR & DE & GR* & IE & IT & NL & PT+ & ES* & SE & UK \\
\hline Web & 17 & 18 & 24 & 25 & 9 & 70 & 5 & 16 & 25 & 48 & 5 & 6 & 61 & 74 \\
\hline Total & - & 6,000 & 3,300 & 5,400 & 74,200 & 89,700 & 16,800 & 4,100 & 67,600 & 10,400 & 14,000 & 39,800 & - & 33,168 \\
\hline W1000 & - & 2.8 & 7.3 & 4.6 & 0.12 & 0.78 & 0.29 & 3.9 & 0.36 & 4.6 & 0.35 & 0.15 & - & 2.2 \\
\hline
\end{tabular}

Source: http://web66.coled.umn.edu/schools/stats/stats.html, and European Commission 1995.

* : Corrections have been made for Greece and Spain. Source: http://wfs.vub.ac.be.

+ : source: National Statistical Yearbooks.

The main and most reliable source of information on the diffusion of WWW in schools, both elementary and secondary, is the International WWW School Registry. In August 1996 there were about 4,600 schools with a Web site. Of these 3,350 are located in the US, and 403 in the EU. ${ }^{38}$ In the total, therefore, the EU is lagging far behind the US. ${ }^{39}$ There are, however, important differences among countries. When we consider the number of WWW sites per 1000 schools (see Table 5), Denmark, Finland, The Netherlands and Ireland have a comparatively high number of schools with Web sites, while France, Spain, Greece, Portugal, Italy and Germany have a low relative number of schools with a WWW site.

\footnotetext{
36 In the count of libraries are included national, non-specialised, public and higher education ones. For Italy and Ireland data were available only for the administrative units, the real number of service points is thus higher than the one we referred. The source of this figures is the UNESCO Statistical yearbook 1994.

37 The source of this and the following figures are different list and directories available on WWW. Among the others, particularly useful are: http://sjcpl.lib.in.us//homepage/P...PubLibSrvsGpherWWW.html, http: // library.usask.ca/hytelnet/sites1b.html, and http://sunsite.berkeley.edu/Libweb/europe.html.

38 In the EU there are about 370,000 schools, then the schools with a web site are circa $0.1 \%$ of the total population.

39 In the last year few projects such as Tele-School Online in the UK, Digischool in The Netherlands and the international Web for Schools are trying to stimulate the connection of schools to the Internet. However, in most of the cased national governments and the European Commission are only marginally, if at all, involved in these projects.
} 
In the EU, the definition of higher education institutions (HEIs) is inconsistent across member states. ${ }^{40}$ To define a benchmark for the analysis of the HEIs with WWW site, we made an estimate starting from the institutions listed on the International Handbook of Universities. This estimate is a lower bound of the number of HEIs in the EU and includes all universities and other education institutions that are equivalent to a university while omitting some of the smaller or more specialised institutions considered as HEIs in other listings. In 1990-1992 in he EU there were about 1,500 HEIs, of which $30 \%$ were universities. A comparable list of colleges and universities with a Web page is compiled by Christina DeMello. ${ }^{41}$ In July 1996, about 580 EU institutions have an active WWW site. Universities comprise the majority of these institutions. Almost all universities in Europe have a Web site, while only some of the equivalent institutions have one. When we analyse the institutions with Web site relative to the total, Finland, Sweden, The Netherlands and Austria show a very high diffusion of WWW sites. All the other countries have lower shares, but none of them can be characterised as 'excluded' from this development. The positive picture painted here reflects the way in which we have constructed the benchmark. If we had included all institutions offering tertiary level programmes for students we would have found a much less positive situation.

The third aspect of the Net that we want to address is the cultural one. By looking under culture in any of the different yellow pages for the Web one may find an endless list of sites with content ranging from the most classic art forms to the new cyber-arts, from classical to avantgarde music and literature in antiquity to modern poetry. However, what we want to assess is not only the existence of available information, but the presence of 'public' places where a citizen can access and learn how to use, or at least become familiar with, the Internet. Therefore, we focused on the presence of museums offering a Web site. We estimate, on the basis of the UNESCO Statistical Yearbook's figures that there are about 9,000 museums in the EU countries. The most detailed list of museums we found with a Web site is the one offered by World Wide Art Resources. ${ }^{42}$ According to this list, in July 1996 there were about 200 EU museums with an active WWW site. By comparing the number of museums with the number of museums with World Wide Web sites Sweden, The Netherlands and Finland stand out with relatively high shares, while Spain, Greece and Portugal have extremely low shares.

Keeping in mind the limitation of the above analyses, especially for the problems in using lists as a means of census, two main conclusions can be drawn. First, in all the EU countries both the education and cultural part of the Internet (measured in term of libraries, schools, institutions

\footnotetext{
40 Some university directories include all the post-secondary institutions, starting from the university down to small organisations granting specialised degrees as HEIs. While other directories include only universities and a few other high-level post-secondary institutions.

41 See http://www.mit.edu:800/people/cdemello/univ.html.

42 See http://wwar.com/museums.html.
} 
of tertiary education and museums with Web sides) are poorly represented compared with their numbers or with the equivalent development of such connections in the U.S. Second, within this general pattern of weakness, there are strong regional imbalances. Cultural institutions in Sweden, The Netherlands and Finland are the most active participants by all the measures used. At the other extreme, Greece, Portugal and Spain are always at the lower end of the distribution.

If it was possible to examine the opportunity to access the Internet from these institutions --i.e. they have an Internet access, but they are not running a server that offers information-- we would find a somewhat higher level of diffusion. Nonetheless, we think that only the existence of a server indicates the presence of higher level capabilities and skills that potentially can be transferred to other people, such as students or citizens using the basic services of the institution. Moreover, as a large part of the population is not yet either computer or network literate, the ease of use of the WWW makes it the more suitable mean for facilitating access to information services. Thus, the existence of servers, and more exactly, of WWW servers, is a reasonable basis for assessing the state of development of access, and for identifying the presence of bottlenecks and structural disadvantage, situations that may require policy interventions.

\section{Internet access cost structure}

The diffusion of Internet access is related to three main factors which influence the structure of demand. First, the level of development of the available ICI (Home PC, Digital Lines, ISDN, Fibre to the Home, Hybrid Fibre Coaxial Cable, Fibre to the Curb, etc.) and the cost of upgrading determine the maximum number of potential users at various levels of service. Second, the skills available (being computer/network literate, being comfortable in using computer interfaces) and the level of support provided determine the number of interested consumers. Third, the costs of obtaining Internet access, including skills building, and individual's or in some cases, organisation's, perception of the value of access determine the number of individuals who become users. All of these factors are undergoing relatively rapid change. For example, the growing use of PCs in the workplace and in HEIs is contributing to a higher level of computer literacy at the same time as widespread publicity about the Internet, and WWW in particular, is raising public interest in the use of the Internet. It would be incorrect to model the demand side of this market in terms of 'fixed' preferences because changing skills and knowledge have a marked impact on user preferences and, at the margin, are probably more influential than the price of access in determining demand. 
In this Section we focus on the third issue, the problem of skills and knowledge building.

Opportunities for skills and knowledge development are closely related to the type of access that individuals may be expected to have: organisational, individual or community. ${ }^{43}$ Each of these types of access has a distinct 'style' for acquiring knowledge and skills.

\section{Organisational}

The typical Internet connection used by large organisation is based on a leased line, usually a T1 line operating at 1.5 Mbps, and a LAN that links terminals and PCs distributed throughout the institution. The management of the system, the supply of services, and the technical and training support are generally run by a specialised department or team within the institution which may, in turn, outsource various parts of their responsibility to outside contractors. Internet access costs are composed by a) the subscription to the service provider, b) the rent of the T1 line, c) a fraction of infrastructural costs (LAN, PC, etc.), and d) a fraction of the management and training costs (the costs of the specialised department or team or the costs of outsourcing these functions). ${ }^{44}$ The final user --i.e. the employee-is unlikely to bear any of these costs but, as noted earlier, may have to comply with use restrictions. In some cases, individual employees will independently invest in their skills to secure a better position or to improve their performance. In any organisation, the costs of providing Internet access (including skills and knowledge development) are substitutes for other investments and, in particular, the use of personnel knowledgeable about information and communication technology to provide Internet access is a substitute for using these individuals to perform other functions in the company.

In larger organisations there is a trend toward providing services to business units based on the provision of budgets which are fungible among different types of service inputs. In the allocation of these budgets, it is often true that 'free rider' problems emerge. A unit may refuse to allocate a portion of its budget for certain types of services under the belief that others will make such a contribution. The result can be a systematic reduction in the number of 'common' resources available in the organisation. This trend will be strengthened by the widespread effort to downsize in which common services in an organisation are often disassembled because support for them is diffuse relative to other services which have strong 'local' support. The result is often a patchwork of critical services, including those in information and

\footnotetext{
43 Estimates suggest that SMEs represent two-thirds of new Internet subscriptions in Europe (including individual companies). A recent survey of 300 European SME users of e-mail, file transfer or on-line services found that Internet is the service of choice for micro companies with less than 10 employees. In smaller SMEs (including the micro-company) skills and knowledge building will be focused on a relatively few individuals who develop competencies primarily for their own use. Larger SMEs are more likely to have specialisation and division of labour and therefore to resemble larger organisations in the way in which they develop competencies.

${ }^{44}$ For example, each year the Maastricht University pays about $\$ 180,000$ of subscription fee and about $\$ 170,000$ for the rental of a $4 \mathrm{Mbps}$ connection line. An upgraded of the line to $34 \mathrm{Mbps}$ IP and $34 \mathrm{Mbps}$ ATM is forecasted in the next 6 to 12 months, the new cost will be of about $\$ 240,000$.
} 
communication technology, with little connective or supportive activity, which can reduce the overall quality of services within the organisation. The 'free rider' problem does not require the explicit mechanism of fungible service budgets. Similar effects will occur in managerial decision-making processes in which an executive seeks to ascertain priority among competing alternatives. These types of effects have had a significant impact on the 'deconstruction' of data processing activities in larger European businesses and the move toward 'client server' architectures. $^{45}$

In the case of the Internet, however, there is a new and important development arising from the growing need for organisations to create, maintain and distribute information in electronic format. The growth of the Internet has induced substantial investment in the creation of new software including browsers, content creation tools, and specialised tools for accessing audiovisual information. The result is an attractive portfolio of 'off the shelf' solutions to the problems of networked information management within the business enterprise. The growth of 'Intranets', private networks using similar tools and techniques such as those used on the public Internet, has been very rapid. With this growth there is a growing familiarity with the tools and methods of Internet use and a growing potential spillover to the use of the Internet. Since private networks most often operate at higher speeds than many of the links on the public Internet, Intranet growth will also create a 'bottom up' demand for better performance on the public network. These developments are likely to be robust and will withstand current downsizing and 'free rider' type problems because the benefits from consolidation of enterprise information in a single easily accessible format and the potential for decentralisation in content creation and maintenance.

As the result of these developments, we may expect larger organisations to make a larger contribution to the development of Internet-related skills and knowledge over time, even though such organisations are making major structural changes in their other data processing activities. From a social viewpoint, this contribution to a common pool of skills for using the Internet is valuable, but it also raises questions about the growing imbalances in the acquisition of these skills.

\section{Individual}

Both home and small enterprises use Internet via a dial-up access. Telephone and ISDN lines, supplied by Public Telecommunication Operators (PTOs) connect the user to an Internet or online service provider offering access to Internet and to other services depending on the type of contract arranged. Internet access costs are composed of: a) the subscription to the service

\footnotetext{
${ }^{45}$ G. Saloner and W. E. Steinmueller (1996) "Demand for Computer Products and Services by Large European Organisations", Report prepared for Amdahl Corporation, Sunnyvale, California.
} 
provider, $\mathrm{b}$ ) the usage costs of the PSTN connection, c) a fraction of hardware costs (usually a PC), and d) skill building and support costs. Subscription and telecommunication costs vary considerably among countries, where infrastructure competition exists, charges are about one third of those in nations with no infrastructure competition (OECD, 1995). In addition, the extent of ISP and OSP penetration in different markets varies widely leading to differences in the timing of discount charges and the diffusion of Points of Presence (POPs). ${ }^{46}$ A sometimes forgotten, but extremely important, component of individual cost structure is the personal investment the user has to make to learn how to use the system. Compared with the use of artefacts like the telephone or TV, using the Internet is very complicated, and substantial knowledge and skill is necessary at the very beginning of the process of getting connected (CSTB, 1996). These costs differ in relation to the age and education of the user and they depend on the presence of a support structure. The existence of an education system that familiarises students with the new technologies reduces the incremental costs that must be paid to achieve access. Recent discussions about the goal of achieving the widest possible access to the information infrastructure have suggested the need for education institutions, both public and private, to have an increasing role in skill and knowledge building. In addition, improvements in support services, both from service providers and hardware sellers, represents a market opportunity which can also be supported by public policy (e.g. recent proposals for an information highway driver's licence would signal the need for a common knowledge base and provide a focus for defining a relevant base of skills and training teachers in the curriculum for such a driving licence examination.

\section{Community}

The cost structure of community access is similar to that of individual access, however the various components have different weights. Only the largest public schools and libraries are large enough to consider a leased line as a means of acquiring service. Nonetheless, the highly identifiable costs of telephone access make a 'piece by piece' upgrading of public access difficult. The school, library or museum of average size will access on-line services through a telephone line or an ISDN. And since schools and libraries have the highest use of communication during the peak daytime hours, the usage costs of connection are an extremely important element in the cost structure.

The problem of establishing a middle ground between telephone access charges and leased line costs presents an important opportunity for promotion of ISDN usage in Europe's public institutions. ISDN connections can be shared by multiple users thereby creating the possibility of higher quality access at affordable cost. ISDN shares the 'time of day' problem with

\footnotetext{
46 The cost of accessing Internet outside local calling areas is extremely high. In the UK different ISPs have a geographical coverage of $80 \%-90 \%$. Demon, through the system of virtual POPs offers $100 \%$ coverage.
} 
telephone line charges, but a relatively small policy change in the tariff practices of PTOs could make a big difference to public access.

\title{
5. Policy action and conclusive remarks
}

\author{
"The High-Performance Computing Act of 1991 (PL 102-194) envisioned libraries \\ as both access points for users to utilise the network as well as providers of \\ information resources via the Internet"(CSTB:135;1994).
}

"Access to networks and services should be equitable, affordable, and ubiquitous." (CSTB:149; 1994).

One approach to reducing the imbalances and disparities that we have identified is to seek the goal of access to public Internet service as a new criterion for universal service throughout Europe. The costs of achieving this goal would be substantial. As we have noted, there are substantial deficiencies in the telecommunications infrastructure, particularly in the lessfavoured regions in Europe, that are accompanied by a similar pattern of deficiency in equipment, knowledge and skills for gaining access. Three major categories of cost are likely to be important. The first is the cost of equipment, which may be dramatically improved by the development of personal computers dedicated to Internet use. The second cost component is telecommunication access which can be significantly reduced by establishing lower tariffs for public ISDN connections. The third cost component is the development of skills and knowledge. Funding this component as a part of basic education would reduce private training costs and would also create substantial spillovers as employers found it easier to hire individuals with basic computer skills. In the United States, the implications of these developments have led to specific plans for improving the implementation of public access. For example:

"For the research and education communities in particular, an increasing emphasis on network-based access to information raises questions about whether there is a need for a minimum level of access -and what that level is, how basic it is in terms of the quality of service (speed, support for video multimedia, and so on), the locus of access (on each desk or on each classroom or in such communal and institutional facilities as libraries), and the breadth of reach (within a state or region, national and/or international, connections to which information provider gateway, and so on)."(CSTB:151;1994) 
To ration community access costs it is possible to imagine a library card which would provide subscribers with a number of hours of access and a ration of assistance in developing user skills to take advantage of this access.

As southern European countries have fewer public institutions such as libraries, universities, and museums, there may have to be additional initiatives supporting 'quasi-public' access sites in these communities, e.g. Internet cafes or the use of public facilities in support of community access.

The most important next steps in the agenda outlined here are the development of concrete cost estimates for attaining access, a thorough debate on the merits of undertaking this goal from a social viewpoint (encompassing an assessment of the validity of the 'broad use' potential of the Internet) and better assessments of the social, i.e. cultural and quality of life and private, i.e. 'wealth creating', implications of a growing social capability to use the new communication medium of the Internet. 


\section{References}

CSTB, 1996, The Unpredictable Certainty. Information Infrastructure Through 2000, National Academy Press, Washington, D.C.

CSTB, 1994, Realising the Information Future. The Internet and Beyond, National Academy Press, Washington, D.C.

European Commission, 1996, Universal Service for Telecommunications in the Perspective of a Fully Liberalised Environment, COM (96)73, Brussels.

B Gregston, 'The European Picture: The Net is Conquering the Old World', Internet World December, pp. 52-57.

High Level Group of Experts, 1996, Building the European Information Society for Us All, Interim Report, European Commission, DGV, Brussels.

Information Society Forum, 1996, Networks for People and their Communities, ECSC-EECEAEC, Brussels.

H. A. Innis, 1964, The Bias of Communication, Toronto: University of Toronto Press.

ITU, 1995, World Telecommunication Development Report, ITU, Switzerland.

A. Kantor and M. Neubarth, 1996, 'Off the Charts: The Internet 1996', Internet World December, pp. 45-51.

M. McLuhan, Understanding Media : The Extensions of Man, London : Routledge, 1994.

R. Mansell and R. Silverstone (eds.), 1996, Communication by Design : The Politics of Communication Technologies, Oxford : Oxford University Press.

C. Marvin, 1988, When Old Technologies Were New : Thinking About Electric Communication in the Late Nineteenth Century, Oxford University Press, 1988.

OECD, 1996, Information Infrastructure Convergence and Pricing: The Internet, DSTI/ICCP/TISP(95)14.

ONPCOM 96-24bis, 1996, 1995 Summary Reports in respect of Council Recommendation 92/383/EEC (on the provision of Harmonised ISDN access arrangements and minimum set of ISDN offerings), European Commission, Brussels. 
N. Rosenberg, Perspectives on Technology, Cambridge University Press, 1976.

G. Saloner and W.E. Steinmueller, 1996, Demand for Computers Products and Services by Large European Organisations, Final Report prepared for Amdahl Corporation, Sunnyvale, California.

S. J. Vaughn-Nichols, 'The NC Follies: A Network Computer is a Small Idea, Internet World December, pp. 72-73. 